\title{
Hydroxypropyl Methylcellulose Phthalate Biopolymer as an Anticorrosion Coating
}

\author{
Shih-Chen Shi \\ Department of Mechanical Engineering, National Cheng Kung University (NCKU), No.1 University \\ Road, Tainan 70101, Taiwan \\ E-mail: scshi@mail.ncku.edu.tw
}

Received: 6 February 2018 / Accepted: 20 July 2021 / Published: 10 August 2021

\begin{abstract}
This study involved a carbohydrate material: hydroxypropyl methyl-cellulose phthalate (HPMCP), a derivative of the biopolymer hydroxypropyl methylcellulose. It is a biodegradable and environmentally friendly material. This study tested the durability and corrosion resistance of HPMCP coatings on highspeed steel in solutions with different $\mathrm{pH}$ values and different immersion durations. The electrochemical tests included potentiodynamic polarization and electrochemical impedance spectroscopy. Water channels formed as the coating dissolved in an acidic environment, which degraded its corrosion resistance. However, with prolonged immersion, the corrosion resistance of the system was maintained because iron oxides and chromium oxides were generated between the HPMCP coating and high-speed steel. The corrosion resistance mechanism of HPMCP coatings is proposed and discussed.
\end{abstract}

Keywords: biopolymer; HPMCP; potentiodynamic polarization; EIS

\section{$\underline{\text { FULL TEXT }}$}

(C) 2021 The Authors. Published by ESG (www.electrochemsci.org). This article is an open access article distributed under the terms and conditions of the Creative Commons Attribution license (http://creativecommons.org/licenses/by/4.0/). 